\title{
DUTY TO MITIGATE THE LOSS: O DEVER DE MITIGAR AS PRÓPRIAS PERDAS
}

\section{Emanuelle Clayre Silva}

\section{RESUMO}

O objetivo deste artigo é realizar um breve estudo acerca da teoria do duty to mitigate the loss. Teoria já consagrada e constantemente utilizada, principalmente nos países de common law, por meio da qual o credor deve mitigar seus próprios prejuízos, caso possua condições de fazê-lo. Assim, haja vista que a cada dia que passa os tribunais brasileiros, o Superior Tribunal de Justiça e a doutrina têm reconhecido sua aplicabilidade no ordenamento jurídico pátrio, necessário se faz a realização deste breve estudo a fim de se tomar conhecimento, ao menos, dos conceitos básicos relativos a esse tema extremamente atual.

Palavras-chave: Duty to mitigate the loss. Responsabilidade civil. Boa-fé objetiva. Abuso de direito- reparação.

\section{INTRODUÇÃO}

O dever de reparar os danos causados a outrem é matéria pautada desde a época da Lei de Talião em que se reparava o mal com o mal, vigorando a regra do "olho por olho" e "dente por dente", ou seja, predominava a vingança privada. 
Conforme a sociedade evoluía, essas regras foram se modificando, a fim de que fosse estabelecido um equilíbrio social, reparando-se os danos e prejuízos das vítimas através das regras e princípios da responsabilidade civil. No decorrer dessa evolução, nascia o seguinte questionamento: até que ponto o credor ou a vítima devem ser ressarcidos pelos prejuízos sofridos? E daí nasciam outros questionamentos: é cabível indenizar o credor ou a vítima pelos prejuízos que eles poderiam ter evitado?

A teoria do duty to mitigate the loss, que será brevemente estudada neste trabalho, trata exatamente desse segundo questionamento. Esta pesquisa, que se deu em maior parte através de teses, monografias e artigos da internet, visto que se trata de tema novo ainda pouco difundido no direito brasileiro, objetiva abordar seu conceito, princípios e aplicação no Brasil.

Por fim, face às poucas referências bibliográficas e eletrônicas quanto a este assunto, sinteticamente será abordada sua aplicação no âmbito da responsabilidade extracontratual.

\section{RESPONSABILIDADE CIVIL}

Os seres humanos, desde o início da civilização, têm necessidade de interagir uns com os outros e viver em sociedade, logo, ubi homo, ibi societas. Tal necessidade fez nascer o Direito, visto que, onde existem relações sociais há a carência de normas que as regulem; disso se extrai o brocardo latino ubi homo, ibi ius, ou seja, onde está o homem, está o Direito.

O Direito busca, através das normas e costumes, viabilizar a convivência em sociedade pelos princípios da ordem e da justiça, a fim de que haja igualdade e não prevaleça a lei do mais forte sobre o mais fraco, do injusto sobre o justo, do ilícito sobre o lícito, visando à solução dos conflitos de interesse presentes em qualquer sociedade.

Daí surge a responsabilidade civil, com o intuito de que aquele que causou danos a outrem arque com os prejuízos que causou devido ao descumprimento de um dever jurídico ou moral, como bem explica Rui Stoco: "a responsabilização é meio e modo de exteriorização da própria 
Justiça e a responsabilidade é a tradução para o sistema jurídico do dever moral de não prejudicar a outro, ou seja, o neminem laedere". ${ }^{1}$

Diversos são os conceitos de responsabilidade aplicados pela doutrina, conforme se pode verificar, partindo dos ensinamentos de Rui Stoco:

Se resumir for possível, pode-se dizer que a responsabilidade civil traduz a obrigação da pessoa física ou jurídica ofensora de reparar o dano causado por conduta que viola um dever jurídico preexistente de não lesionar (neminem laedere) implícito ou expresso em lei. ${ }^{2}$

Para Silvio de Salvo Venosa:

O termo responsabilidade é utilizado em qualquer situação na qual alguma pessoa, natural ou jurídica, deva arcar com as consequências de um ato, fato, ou negócio danoso. Sob essa noção, toda atividade humana, portanto, pode acarretar o dever de indenizar. $^{3}$

Sérgio Cavalieri Filho conceitua: "responsabilidade civil é um dever jurídico sucessivo que surge para recompor o dano decorrente da violação de um dever jurídico originário."4

De tal modo, apesar da divergência de opiniões dos doutrinadores, basicamente a mesma linha de raciocínio é seguida ao se entender que a finalidade da responsabilidade civil é reparar o equilíbrio social por meio do poder judiciário, pois um dano não reparado ocasiona instabilidade nas relações sociais, devendo todo dano ser reparado por seu causador.

\footnotetext{
${ }^{1}$ STOCO, Rui. Tratado de responsabilidade civil, 6 ed., São Paulo: Revista dos Tribunais, 2004. p. 118

2 Ibidem. p. 120.

${ }^{3}$ VENOSA, Silvio de Salvo. Direito Civil: responsabilidade civil. 10. ed. São Paulo: Atlas, 2010, v. 4, p. 1.

${ }^{4}$ CAV ALIERI FILHO, Sergio. Programa de responsabilidade civil. 10. ed. São Paulo: Atlas, 2012, p. 2.
} 
Quanto ao seu fato gerador, a responsabilidade civil divide-se em contratual ou extracontratual. A responsabilidade contratual surgirá do inadimplemento de um contrato, proveniente de um negócio jurídico bilateral ou unilateral, ou seja, de um negócio jurídico pré-existente entre as partes contratantes. Na responsabilidade extracontratual, o dever jurídico a ser cumprido vem da vontade do Estado, dimana da lei, ou seja, do neminem laedere, a obrigação de não causar dano a ninguém.

\section{O PRINCÍPIO DA REPARAÇÃO INTEGRAL}

O Código Civil de 2002, quanto ao dever de indenizar decorrente responsabilidade civil, adotou o princípio da reparação integral do dano,

cuja origem "é o Direito francês, tendo sido sintetizado pela doutrina com um adágio: "tout le dommage, mais rien que le dommage" ("todo o dano, mas nada mais do que o dano")". 5

Tal princípio encontra-se presente no artigo $944{ }^{6}$ do Código Civil de 2002, ao determinar que a indenização deva ser medida pela extensão dos danos causados à vítima.

As decisões dos Tribunais brasileiros, a partir da observância do referido artigo, são proferidas no seguinte sentido: "vige, no ordenamento brasileiro, o sistema da reparação integral, segundo o qual o quantum da indenização deve ser proporcional à extensão dos danos, não guardam relação com a situação econômico-financeira das partes" (TJ-RS - AC: 70039938048 RS, Relator: Umberto Guaspari Sudbrack, Data de Julgamento: 30/08/2012, Décima Segunda Câmara Cível, Publicação: Diário da Justiça de 03/09/2012).

Todavia, o parágrafo único do citado artigo 944 comporta exceções ao disposto no caput, ao disciplinar que "se houver excessiva desproporção entre a gravidade da culpa e o dano, poderá o juiz reduzir, equitativamente, a indenização".

${ }^{5}$ SANSEVERINO, Paulo de Tarso V. O Princípio da Reparação Integral e os Danos Pessoais. Disponível em:<http://www.cartaforense.com.br/conteudo/artigos/o-principioda-reparacao-integral-e-os-danos-pessoais/4768>. Acesso em: 04/12/2013.

6 “Art. 944. A indenização mede-se pela extensão do dano. Parágrafo único. Se houver excessiva desproporção entre a gravidade da culpa e o dano, poderá o juiz reduzir, equitativamente, a indenização." 
Desse modo, caso o magistrado verifique que o agente não teve intenção de causar dano, poderá reduzir a indenização a vítima, como bem explica Pablo Stolze Gagliano:

Ora, tal permissivo, subvertendo o princípio de que a indenização mede-se pela extensão do dano, permite que o juiz investigue culpa para o efeito de reduzir o quantum debeatur. É o caso, por exemplo, de o magistrado constatar que o infrator não teve intenção de lesionar, embora haja causado dano considerável. 7

Extrai-se daí que a extensão do dano deixou de ser critério indiscutível para apuração da reparação dos danos indenizáveis.

Nesse sentido, Christian Sahb Batista Lopes, no tocante a reparação integral do dano no direito brasileiro, ensina que o disposto no caput do artigo 944 do Código Civil não é absoluto, comportando exceções:

A regra de reparação integral não pode, entretanto, ser tida como princípio absoluto e insuperável do direito brasileiro e, de fato, não é. Além de excepcionada pelo parágrafo único, a reparação integral é limitada pelo artigo 403, que determina que apenas os danos diretos e imediatos podem ser indenizados. $^{8}$

Conforme exposto acima, resta claro que, no ordenamento jurídico brasileiro, não vige de forma soberana o princípio da reparação integral dos danos, visto que, não obstante a exceção prevista no parágrafo

7 GAGLIANO, Pablo Stolze; PAMPLONA FILHO, Rodolfo. Novo curso de direito civil. 10 ed. São Paulo: Saraiva, 2012, v.3. p.183.

${ }^{8}$ LOPES, Christian Sahb Batista. A mitigação dos prejuízos no direito contratual. Tese (Doutorado em Direito) - Programa de Pós-Graduação em Direito da Faculdade de Direito, Universidade Federal de Minas Gerais, Belo Horizonte, 2011. Disponível em: $<$ http://www.bibliotecadigital.ufmg.br/dspace/bitstream/handle/1843/BUOS-

8MQG8H/tese__christian_s_b_lopes__a_mitiga_o_dos_preju_zos_no_direito_contra tual.pdf?sequence $=1>$. Acesso em 22/10/2013. p. 171 . 
único do já citado artigo 944, constitui exceção a esse princípio o disposto no artigo 403 do mesmo diploma legal.

Dispõe o artigo 403 do Código Civil brasileiro:

Art. 403. Ainda que a inexecução resulte de dolo do devedor, as perdas e danos só incluem os prejuízos efetivos e os lucros cessantes por efeito dela direto e imediato, sem prejuízo do disposto na lei processual.

Por conseguinte, além das citadas exceções ao princípio da reparação integral, o entendimento atual é o de que a teoria do duty to mitigate the loss, constitui uma exceção a esse princípio, conforme se verificará a seguir.

\section{A BOA-FÉ OBJETIVA}

O princípio da boa-fé pressupõe o dever das partes de agir de forma correta e íntegra durante as negociações do contrato e seu cumprimento. Esse princípio está relacionado ao princípio de direito que afirma que ninguém pode se beneficiar de seu comportamento torpe. ${ }^{9}$

O princípio da boa-fé se divide em boa-fé subjetiva ou concepção psicológica da boa-fé, e boa-fé objetiva ou concepção ética da boafé. ${ }^{10}$

Giselda Hironaka citada por Pablo Stolze Gagliano e Rodolfo Pamplona Filho, no que se refere à diferença entre a boa-fé objetiva e a subjetiva afirma:

A mais célebre das cláusulas gerais é exatamente a da boa-fé objetiva nos contratos. Mesmo levando-se em consideração o extenso rol de vantagens e de desvantagens que a presença de cláusulas gerais pode gerar num sistema de direito, provavelmente a

\footnotetext{
${ }^{9}$ GONÇALVES, Carlos Roberto. Direito civil brasileiro: contratos e atos unilaterais. 9 ed., São Paulo: Saraiva, 2011. v. 3. p. 54

${ }^{10}$ Idem. p. 55.
} 
cláusula da boa-fé objetiva, nos contratos, seja mais útil que deficiente, uma vez que, por boa-fé, se entende que é um fato (que é psicológico) e uma virtude (que é moral). ${ }^{11}$

Neste estudo, a análise e compreensão da boa-fé objetiva é o que mais interessa, pois, conforme já fora citado, entende-se que a teoria do duty to mitigate the loss, no direito brasileiro, está estritamente ligada a esse princípio.

A boa-fé objetiva possui, como principal função, estabelecer um padrão de conduta ético entre as partes nas relações obrigacionais; contudo, esse padrão ético de conduta não se faz presente apenas no campo das relações obrigacionais, como também em todos os campos do direito.

Deste modo, tendo em vista que a boa-fé objetiva exterioriza-se como uma forma de conduta a ser seguida pelos indivíduos e que deve ser ética, proba e leal, não há de se falar em confusão com a boa-fé subjetiva, pois essa pode ser entendida como um estado de consciência.

Denise de Araújo Capiberibe, no tocante ao princípio da boa-fé objetiva, esclarece:

Com efeito, a noção de boa-fé objetiva no contexto atual do Direito Civil está profundamente ligada ao valor ético, o qual se alinha com os conceitos de lealdade, correção, veracidade e justa expectativa, que compõem o seu substrato e lhe dão suporte.

A boa-fé objetiva, portanto, é um dos princípios contemporâneos da Teoria Contratual. Sob tal prisma, age de forma a realizar os valores do Estado Democrático de Direito. ${ }^{12}$

\footnotetext{
11 GaglianO, Pablo Stolze; PAMPLONA FILHO; Rodolfo. Novo curso de direito civil: contratos. 8 ed. São Paulo: Saraiva, 2012, v.4. p. 111.

12 CAPIBERIBE, Denise de Araújo. O princípio da boa-fé objetiva e sua evolução doutrinária e jurisprudencial ao longo dos 10 anos de edição do novo código civil. Disponível em: <http://www.emerj.tjrj.jus.br/serieaperfeicoamentodemagistrados/paginas/series/13/volum eI/10anosdocodigocivil_117.pdf> Acesso em: 03/12/2013.
} 
aduz:

Carlos Roberto Gonçalves, referente ao princípio em questão,

[...] a objetiva, que se constitui em uma norma jurídica fundada em um princípio geral do direito, segundo o qual todos devem comportar-se de boa-fé nas suas relações recíprocas.

Classifica-se, assim, como regra de conduta. Incluída no direito positivo de grande parte dos países ocidentais, deixa de ser princípio geral de direito para transformar-se em cláusula geral de boa-fé objetiva. É, portanto, fonte de direito e de obrigações. $^{13}$

A análise para se concluir se a parte estava agindo ou não com boa-fé não é simples, tendo em vista que diversos fatores devem ser sopesados para se chegar a essa conclusão, como bem explica o ministro Humberto Martins do Superior Tribunal de Justiça:

"Reconhecer a boa-fé não é tarefa fácil [...]. Para concluir se o sujeito estava ou não de boa-fé, tornase necessário analisar se o seu comportamento foi leal, ético, ou se havia justificativa amparada no direito $[\ldots]{ }^{14}$

Sinteticamente, pode-se dizer que o descumprimento do dever geral da boa-fé objetiva gera as mesmas consequências que a prática de qualquer ato ilícito, ou seja, o dever de indenizar a outrem pelos prejuízos que lhe causar.

No Brasil, esse princípio foi positivado no Código Civil de 2002, sendo citado expressamente nos artigos 113, 187 e 422.

13 GONÇALVES, Carlos Roberto. Direito civil brasileiro: contratos e atos unilaterais. 9 ed., São Paulo: Saraiva, 2011. v. 3. p. 56.

${ }^{14}$ Superior Tribunal de Justiça. Princípio da boa-fé objetiva é consagrado pelo STJ em todas as áreas do direito. Disponível em: <http://www.stj.jus.br/portal_ stj/publicacao/engine.wsp?tmp.area=398\&tmp.texto=108925>. Acesso em: 03/12/2013. 


\section{DUTY TO MITIGATE THE LOSS}

Conforme previamente analisado, a prática de atos ilícitos, a violação de um contrato adrede celebrado ou do neminem laedere são pressupostos para que nasça a responsabilidade civil contratual e extracontratual. Não há dúvidas de que se deve reparar a vítima ou credor pelos prejuízos sofridos em face do inadimplemento ou da prática de um ilícito causador de dano. Assim, a teoria do duty to mitigate the loss também conhecida como doutrina dos danos evitáveis pode ser traduzida como o dever de mitigar as próprias perdas. Entretanto, segundo essa teoria, é o credor quem possui o dever de mitigar suas perdas ou seu próprio prejuízo mediante esforço razoável.

Quanto à origem do tema, aborda-se teoria já estudada em diversos países, conforme ensina Vera Maria Jacob Fradera, citada por Flávio Tartuce, ao aduzir que "o dever de mitigar, atribuído ao credor, mitigate - tem origem no direito anglo-saxão, de onde passou para os sistemas jurídicos continentais. $\mathrm{O}$ vocábulo mitigate tem raiz francesa, provém do verbo mitiger". ${ }^{15}$

Nos países de common law, no direito contratual "a reparação das perdas e danos suportados pelo credor comporta três limitações: imprevisibilidade, incerteza e evitabilidade." ${ }^{16}$ Essa terceira limitação, a chamada evitabilidade está adstrita ao dever de mitigar (duty to mitigate).

Sendo assim, a possibilidade que o credor possui de evitar que o dano venha a ocorrer constitui uma limitação à reparação das perdas e danos, como bem explica Christian Sahb Batista Lopes:

A terceira limitação à reparação das perdas e danos consiste no chamado dever mitigar (duty to mitigate) ou doutrina dos danos evitáveis. De acordo com essa

\footnotetext{
${ }^{15}$ FRADERA, Vera Maria Jacob apud TARTUCE, Flávio. A boa-fé objetiva e a mitigação do prejuízo pelo credor. Esboço do tema e primeira abordagem. 2005. Disponível em: <http://www.flaviotartuce.adv.br/index2.php?sec=artigos\&totalPage=2>. Acesso em 03/12/2013.

16 LOPES, Christian Sahb Batista. A mitigação dos prejuízos no direito contratual. Tese (Doutorado em Direito) - Programa de Pós-Graduação em Direito da Faculdade de Direito, Universidade Federal de Minas Gerais, Belo Horizonte, 2011. Disponível em: <http://www.bibliotecadigital.ufmg.br/dspace/bitstream/handle/1843/BUOS-

8MQG8H/tese__christian_s_b_lopes__a_mitiga_o_dos_preju_zos_no_direito_contra tual.pdf?sequence=1>. Acesso em 22/10/2013.p. 19
} 
norma, o credor, prejudicado por um inadimplemento, não será indenizado pelas perdas e danos que evitou ou poderia ter evitado com esforços razoáveis e apropriados às circunstâncias. ${ }^{17}$

Interessante mencionar que, segundo o autor supracitado, quase toda a doutrina inglesa e norte-americana entende que não há um dever de mitigar, mas uma limitação, visto que "se houvesse, a mitigação poderia ser exigida pela parte inadimplente e a parte prejudicada estaria sujeita a indenizar se não adotasse as medidas necessárias para a mitigação". ${ }^{18}$

Dessa forma, se a parte contratante não adotar medidas a fim de minimizar o prejuízo, a indenização a que fará jus ficará adstrita ao que era impossível que ela evitasse. ${ }^{19}$

Destarte, o objetivo principal dessa teoria é afastar o desperdício de recursos econômicos ao indenizar o credor por danos que este poderia ter evitado sem grandes esforços, possuindo, para tanto, dois estímulos: de um lado nega ao credor o direito de ser indenizado por se quedar inerte; e por outro concede o direito à reparação pelos esforços empregados na tentativa de diminuição das perdas. ${ }^{20}$

No direito norte-americano, assim como no direito contratual inglês é indiscutível a aplicabilidade dessa teoria, também presente em países como a Alemanha, Itália e França. ${ }^{21}$

Porém, nesses países de civil law os fundamentos encontrados para aplicação dessa teoria foram diversos, desde "imprevisibilidade dos

${ }^{17}$ LOPES, Christian Sahb Batista. A mitigação dos prejuízos no direito contratual. Tese (Doutorado em Direito) - Programa de Pós-Graduação em Direito da Faculdade de Direito, Universidade Federal de Minas Gerais, Belo Horizonte, 2011. Disponível em: <http://www.bibliotecadigital.ufmg.br/dspace/bitstream/handle/1843/BUOS-

8MQG8H/tese__christian_s_b_lopes__a_mitiga_o_dos_preju_zos_no_direito_contra tual.pdf?sequence $=1>$. Acesso em 22/10/2013. p. 20

18 Idem. p. 23.

${ }^{19}$ Ibidem.

${ }^{20}$ Idem. p. 50.

${ }^{21}$ LOPES, Christian Sahb Batista. A mitigação dos prejuízos no direito contratual. Tese (Doutorado em Direito) - Programa de Pós-Graduação em Direito da Faculdade de Direito, Universidade Federal de Minas Gerais, Belo Horizonte, 2011. Disponível em: <http://www.bibliotecadigital.ufmg.br/dspace/bitstream/handle/1843/BUOS-

8MQG8H/tese__christian_s_b_lopes__a_mitiga_o_dos_preju_zos_no_direito_contra tual.pdf?sequence=1>. Acesso em 22/10/2013. p. 12. 
danos, ausência de causalidade, dano indireto, a culpa concorrente, o fato ou culpa do credor, a violação ao dever de boa-fé, o abuso de direito e venire contra factum proprium". ${ }^{22} \mathrm{O}$ que não ocorre na common law, visto que apesar de inquestionável sua aceitação, não é pacífico o fundamento jurídico do dever de mitigar os danos.

\section{A APLICAÇÃO DO DUTY TO MITIGATE THE LOSS NO DIREITO BRASILEIRO}

Referente à aplicação dessa teoria no direito brasileiro, Daniel Pires Novais Dias afirma:

O Direito civil brasileiro vive fenômeno de teorização e aplicação judicial do duty to mitigate the loss. Este fenômeno originou-se de proposta doutrinária para solucionar o problema de imputação de danos nas situações em que o credor, em face do inadimplemento do contrato, não adota medidas razoáveis para evitar ou minimizar o próprio prejuízo. Posteriormente ampliou-se para abarcar situações de responsabilidade civil aquiliana e de exercício tardio de direito que implica em ônus excessivo para o devedor. ${ }^{23}$

No Brasil, no ano de 2004, Vera Maria Jacob de Fradera realizou proposta na III Jornada de Direito Civil do Conselho da Justiça Federal com a finalidade de que fosse confeccionado um enunciado prevendo a mitigação dos prejuízos na responsabilidade contratual em razão de violação ao princípio da boa-fé objetiva, baseando-se no artigo 422 do Código Civil vigente. A proposta foi aprovada, sendo criado o Enunciado

\footnotetext{
${ }^{22}$ Idem. p. 128.

${ }^{23}$ LOPES, Christian Sahb Batista. A mitigação dos prejuízos no direito contratual. Tese (Doutorado em Direito) - Programa de Pós-Graduação em Direito da Faculdade de Direito, Universidade Federal de Minas Gerais, Belo Horizonte, 2011. Disponível em: <http://www.bibliotecadigital.ufmg.br/dspace/bitstream/handle/1843/BUOS8MQG8H/tese__christian_s_b_lopes__a_mitiga_o_dos_preju_zos_no_direito_contra tual.pdf?sequence $=1>$. Acesso em 22/10/2013. p. 128 .
} 
n. ${ }^{\circ} 169$ do CJF/STJ, dispondo que "o princípio da boa-fé objetiva deve levar o credor a evitar o agravamento do próprio prejuízo".

Esse enunciado fora inspirado no artigo 77 da Convenção de Viena de 1980, sobre venda internacional de mercadorias que dispõe:

A parte que invoca a violação do contrato deve tomar as medidas razoáveis, face às circunstâncias, para limitar a perda, aí compreendido o lucro cessante, resultante da violação contratual. Se não o fizer, a parte faltosa pode pedir uma redução da indenização por perdas e danos, no montante da perda que deveria ter sido evitada. ${ }^{24}$

No que se refere à aprovação da proposta elaborada por Fradera, Flávio Tartuce afirma:

A proposta, elaborada por Vera Maria Jacob de Fradera, professora da Universidade Federal do Rio Grande do Sul, representa muito bem a natureza do dever de colaboração, presente em todas as fases contratuais e que decorre do princípio da boa-fé objetiva e daquilo que consta do art. 422 do CC. ${ }^{25}$

Fradera entende que há uma relação direta entre a mitigação dos danos com a boa-fé objetiva, tendo em vista que esta mitigação consistiria em um dever de natureza complementar, que teria seu fundamento no dever de boa conduta que deve existir entre as partes contratantes. ${ }^{26}$

Através da observância do princípio da boa-fé objetiva, deverá o credor evitar a majoração do próprio prejuízo, à medida que a violação

\footnotetext{
${ }^{24}$ Convenção da ONU sobre os contratos de compra e venda internacional de mercadorias. Disponível em: 〈http://www.globalsaleslaw.org/_temp/CISG_portugues.pdf〉. Acesso em 04/12/2013.

25 TARTUCE, Flávio. Manual de direito civil. Rio de Janeiro: Forense; São Paulo: Método. 2011. v. único. p. 515.

26 TARTUCE, Flávio. A boa-fé objetiva e a mitigação do prejuízo pelo credor. Esboço do tema e primeira abordagem. 2005. Disponível em: <http://www.flaviotartuce.adv.br/index2.php?sec=artigos\&totalPage=2>. Acesso em $03 / 12 / 2013$.
} 
do dever de mitigar suas próprias perdas pode ser entendida como ato ilícito que infringe, pois, a própria cláusula geral da boa-fé objetiva.

$\mathrm{O}$ artigo 422 do Código Civil brasileiro trata expressamente do princípio da boa-fé objetiva ao dispor que "os contratantes são obrigados a guardar, assim na conclusão do contrato, como em sua execução, os princípios de probidade e boa-fé".

Flávio Tartuce apresenta alguns exemplos da aplicação dessa teoria no ordenamento jurídico pátrio:

Exemplificando a aplicação do duty do mitigate the loss, pensemos no caso de um contrato de locação de imóvel urbano em que houve inadimplemento. Ora, nesse negócio, haveria um dever por parte do locador de ingressar tão logo seja possível com a competente ação de despejo, não permitindo que a dívida assuma valores excessivos.

Mesmo argumento vale para os contratos bancários em que há descumprimento. Segundo a nossa interpretação, não pode a instituição financeira permanecer inerte, aguardando que, diante da alta taxa de juros prevista no instrumento contratual, a dívida atinja montantes astronômicos. ${ }^{27}$

Os tribunais brasileiros têm aplicado essa teoria aos casos práticos na forma apresentada por Vera Maria Jacob Fradera, fundamentando suas decisões nos artigos 422 e 187 do Código Civil. Evidencia a jurisprudência:

\begin{tabular}{|c|c|c|}
\hline ¿̃o. & COBRANÇA. & \\
\hline CONDOMINIAIS & VENCIDAS. & BOA-FÉ \\
\hline BJETIVA. DUTY & IGATE & S. \\
\hline RTIGO 77 DA & CONVENÇÃO & VIE \\
\hline FENSA NÃO CO & NFIGURADA. F & ISÃC \\
\hline ARTIGO 475-J DO & CPC. MERA A & $\mathrm{EN}$ \\
\hline O DEVER & DE MITIGAR & RÓP \\
\hline & & \\
\hline
\end{tabular}

${ }^{27}$ Ibidem. 
QUE, TÃO LOGO TOME CONHECIMENTO DA MORA POR PARTE DO DEVEDOR, INGRESSE COM A MEDIDA CABÍVEL, A FIM DE SATISFAZER SEU CRÉDITO, DE MODO A NÃO AUMENTAR O PREJUÍZO DO DEVEDOR[...]. (TJ-DF - APC: 20120410097209 DF 000943597.2012.8.07.0004, Relator: JOÃO EGMONT, Data de Julgamento: 31/07/2013, $5^{\text {a }}$ Turma Cível, Data de Publicação: Publicado no DJE: 05/08/2013. Pág.: 173)

[...] CRITÉRIO DE CÁLCULO. ABUSIVIDADE. DUTY TO MITIGATE THE LOSS. Os critérios de cálculo da Resolução 456/2000 da ANEEL, no caso concreto, se afiguram abusivos, em decorrência da aplicação do princípio da boa-fé. A ré tinha ciência, há mais de cinco anos, da existência de irregularidades na UC do autor, o que lhe impunha o dever de realizar diligências, que estavam ao seu alcance, a fim de mitigar seu prejuízo (duty to mitigate the loss). Nesse contexto, e considerando que a prova dos autos não permite que se estabeleça com precisão a data do início da irregularidade, o cálculo do débito de recuperação do consumo não medido deva ser realizado tendo por base a média do efetivo consumo dos 12 meses posteriores à substituição do medidor (critério de cálculo que se revela mais benéfico ao autor), prestigiando-se, dessa forma, tanto a vedação ao enriquecimento sem causa como a boa-fé objetiva[...].(TJ-RS - AC: 70046205951 RS, Relator: Denise Oliveira Cezar, Data de Julgamento: 23/02/2012, Vigésima Segunda Câmara Cível, Data de Publicação: Diário da Justiça do dia 29/02/2012)

Ainda, o Superior Tribunal de Justiça já consolidou seu entendimento no sentido da aplicabilidade da teoria do "duty to mitigate the loss" aos casos concretos:

DIREITO CIVIL. CONTRATOS. BOA-FÉ OBJETIVA. STANDARD ÉTICO-JURÍDICO. OBSERVÂNCIA PELAS PARTES CONTRATANTES. DEVERES ANEXOS. DUTY 
TO MITIGATE THE LOSS. DEVER DE MITIGAR O PRÓPRIO PREJUÍZO. INÉRCIA DO CREDOR. AGRAVAMENTO DO DANO. INADIMPLEMENTO CONTRATUAL. RECURSO IMPROVIDO. 1. Boa-fé objetiva. Standard éticojurídico. Observância pelos contratantes em todas as fases. Condutas pautadas pela probidade, cooperação e lealdade. 2. Relações obrigacionais. Atuação das partes. Preservação dos direitos dos contratantes na consecução dos fins. Impossibilidade de violação aos preceitos éticos insertos no ordenamento jurídico. 3. Preceito decorrente da boa-fé objetiva. Duty to mitigate the loss: o dever de mitigar o próprio prejuízo. Os contratantes devem tomar as medidas necessárias e possíveis para que o dano não seja agravado. A parte a que a perda aproveita não pode permanecer deliberadamente inerte diante do dano. Agravamento do prejuízo, em razão da inércia do credor. Infringência aos deveres de cooperação e lealdade. 4. Lição da doutrinadora Véra Maria Jacob de Fradera. Descuido com o dever de mitigar o prejuízo sofrido. $\mathrm{O}$ fato de ter deixado o devedor na posse do imóvel por quase 7 (sete) anos, sem que este cumprisse com o seu dever contratual (pagamento das prestações relativas ao contrato de compra e venda), evidencia a ausência de zelo com o patrimônio do credor, com o consequente agravamento significativo das perdas, uma vez que a realização mais célere dos atos de defesa possessória diminuiriam a extensão do dano. 5. Violação ao princípio da boa-fé objetiva. Caracterização de inadimplemento contratual a justificar a penalidade imposta pela Corte originária, (exclusão de um ano de ressarcimento). 6. Recurso improvido. (STJ REsp: 758518 PR 2005/0096775-4, Relator: Ministro VASCO DELLA GIUSTINA (DESEMBARGADOR CONVOCADO DO TJ/RS), Data de Julgamento: 17/06/2010, T3 - TERCEIRA TURMA, Data de Publicação: DJe 28/06/2010 REPDJe 01/07/2010) 
Salienta-se que a teoria do dever de mitigar o dano atualmente não é utilizada apenas na esfera cível, utilizando-a inclusive no âmbito Criminal $^{28}$ e da Justiça do Trabalho ${ }^{29}$.

O dever de mitigar possui alguns pressupostos, limites e efeitos, que podem ser estabelecidos por algumas regras, consoante Christian Sahb Batista Lopes:

(a) O credor não será indenizado pelos danos decorrentes do inadimplemento que pudessem ser evitados ou reduzidos com o emprego de medidas ou esforços razoáveis de sua parte.

(b) A indenização devida ao credor deverá ser reduzida no montante dos ganhos por ele obtidos que não seriam auferidos se não fosse o inadimplemento.

(c) O credor deverá ser indenizado pelas despesas razoáveis feitas na tentativa de evitar ou reduzir os danos decorrentes do inadimplemento. ${ }^{30}$

Para Vera Maria Jabob Fradera, a mitigação tem natureza de um dever anexo e não de uma obrigação, ao passo que sua violação pode ser compreendida como uma culpa delitual. ${ }^{31}$

Em contrapartida, Christian Sahb Batista Lopes não possui o mesmo posicionamento, pois acredita que a mitigação não possui natureza de dever, mas sim de ônus jurídico, já que se o credor age para evitar

28 STJ - HC: 266426 SC 2013/0070770-4, Relator: Ministra MARIA THEREZA DE ASSIS MOURA, Data de Julgamento: 07/05/2013, T6 - SEXTA TURMA, Data de Publicação: DJe 14/05/2013.

29 TRT-2 - RO: 22015620125020 SP 20130026104, Relator: MERCIA TOMAZINHO, Data de Julgamento: 07/05/2013, 3ª TURMA, Data de Publicação: 15/05/2013.

${ }^{30}$ LOPES, Christian Sahb Batista. A mitigação dos prejuízos no direito contratual. Tese (Doutorado em Direito) - Programa de Pós-Graduação em Direito da Faculdade de Direito, Universidade Federal de Minas Gerais, Belo Horizonte, 2011. Disponível em: <http://www.bibliotecadigital.ufmg.br/dspace/bitstream/handle/1843/BUOS-

8MQG8H/tese__christian_s_b_lopes__a_mitiga_o_dos_preju_zos_no_direito_contra tual.pdf?sequence $=1>$. Acesso em 22/10/2013. p. 247 .

31 TARTUCE, Flávio. A boa-fé objetiva e a mitigação do prejuízo pelo credor. Esboço do tema e primeira abordagem. 2005. Disponível em: $<$ http://www.flaviotartuce.adv.br/index2.php?sec=artigos\&totalPage=2>. Acesso em $03 / 12 / 2013$. 
os prejuízos, terá direito à reparação integral, se não agir, não terá direito à reparação pelos prejuízos que poderiam ser evitados. ${ }^{32}$

Cabe destacar que caberá ao devedor, o ônus de provar que o credor poderia ter mitigado as próprias perdas e qual a amplitude dos danos que ele poderia ter evitado.

No que concerne ao posicionamento de o dever de mitigar ser uma exceção ao princípio da reparação integral, justifica-se, pois "o princípio da mitigação tem justificativas morais, sociais e econômicas que têm força maior que a explicação para a compensação integral ao credor." 33

De acordo com Christian Sahb Batista Lopes, "a boa-fé objetiva poderá ter atuação defensiva, isto é, ter por efeito impedir que a pessoa que agiu de ma-fé exerça certo direito ou se valha de certa posição jurídica", dessarte o credor que sofrer com o inadimplemento do devedor terá direito a reparação integral dos danos sofridos, porém, se não empregar seus esforços visando evitar que prejuízos ocorram ou que determinada situação se agrave, não fará jus à indenização integral, apenas a parcela dos prejuízos inevitáveis. ${ }^{34}$

Por fim, no Brasil essa exceção ao princípio da reparação integral dos danos aplicada a partir da violação da boa-fé objetiva, vem sendo gradativamente aplicada, conforme se pode ver nos julgados previamente transcritos.

\subsection{Abuso de direito e venire contra factum proprium}

\footnotetext{
32 LOPES, Christian Sahb Batista. A mitigação dos prejuízos no direito contratual. Tese (Doutorado em Direito) - Programa de Pós-Graduação em Direito da Faculdade de Direito, Universidade Federal de Minas Gerais, Belo Horizonte, 2011. Disponível em: <http://www.bibliotecadigital.ufmg.br/dspace/bitstream/handle/1843/BUOS-

8MQG8H/tese__christian_s_b_lopes__a_mitiga_o_dos_preju_zos_no_direito_contra tual.pdf? sequence $=1>$. Acesso em 22/10/2013. p. 248 .

33 Ibidem. p. 172.

34 LOPES, Christian Sahb Batista. A mitigação dos prejuízos no direito contratual. Tese (Doutorado em Direito) - Programa de Pós-Graduação em Direito da Faculdade de Direito, Universidade Federal de Minas Gerais, Belo Horizonte, 2011. Disponível em: <http://www.bibliotecadigital.ufmg.br/dspace/bitstream/handle/1843/BUOS-

8MQG8H/tese__christian_s_b_lopes__a_mitiga_o_dos_preju_zos_no_direito_contra tual.pdf?sequence $=1>$. Acesso em 22/10/2013. p. 173 .
} 
Vera Maria Jacob Fradera, ao descrever suas razões para a adoção desse tema ao direito brasileiro, baseando-se no direito francês, afirma ser possível sua aplicação também em decorrência do venire contra factum proprium e do abuso de direito:

Outro aspecto a ser destacado, é o da positivação do princípio da boa fé objetiva, no novo diploma civil, abrindo, então, inúmeras possibilidades ao alargamento das obrigações e /ou incumbências das partes, no caso, as do credor.

Como se isso não fora suficiente fundamento para adoção desse dever, restam ainda, sob o influxo da jurisprudência francesa, duas possibilidades de justificar a recepção: o conceito de venire contra factum proprium e o de abuso de direito, cuja previsão representa, segundo uma doutrina minoritária, um avanço do novo Código Civil, em relação ao anterior, omisso nesta parte. ${ }^{35}$

O posicionamento da maioria dos autores é contrário à aplicação do dever de mitigar em razão do abuso de direito ou do venire contra factum proprium.

O artigo 187 do Código Civil brasileiro dispõe que "também comete ato ilícito o titular de um direito que, ao exercê-lo, excede manifestamente os limites impostos pelo seu fim econômico ou social, pela boa-fé ou pelos bons costumes".

Por abuso de direito, Silvio Rodrigues, citado por Rui Stoco, sustenta que:

$\mathrm{O}$ abuso de direito ocorre quando o agente, atuando dentro das prerrogativas que o ordenamento jurídico lhe concede, deixa de considerar a finalidade social do direito subjetivo, e, ao utilizá-lo desconsideradamente causa dano a outrem. Aquele que exorbita no exercício de seu direito, causando

\footnotetext{
35 TARTUCE, Flávio. A boa-fé objetiva e a mitigação do prejuízo pelo credor. Esboço do tema e primeira abordagem. 2005. Disponível em: $<$ http://www.flaviotartuce.adv.br/index2.php?sec=artigos\&totalPage=2>. Acesso em $03 / 12 / 2013$
} 
prejuízo a outrem, pratica ato ilícito, ficando obrigado a reparar. Ele não viola os limites objetivos da lei, mas embora os obedeça, desvia-se dos fins sociais a que se destina, do espírito que a norteia. ${ }^{36}$

Para Christian Sahb Batista Lopes, "o fundamento da mitigação não pode ser encontrado na concepção subjetiva do abuso de direito, salvo em situações excepcionais". ${ }^{37}$

Logo, o referido autor ainda aduz:

Desta forma, conclui-se que a teoria do abuso de direito, desde que tomada em seu aspecto objetivo, pode ser tida como um dos aspectos da mitigação. Contudo, a teoria do abuso de direito não pode ser tida como um fundamento a mais, mas apenas como ratificação da conclusão a que se chegou anteriormente que a norma de mitigação tem seu fundamento na boa-fé, pois apenas quando a teoria do abuso de direito se assenta nesta noção é que terá contato com a evitabiliadade. ${ }^{38}$

O posicionamento é que se deve manter a fundamentação da mitigação na boa-fé separadamente do abuso de direito, visto que não é necessário se recorrer à teoria do abuso de direito, já que esta se conecta

${ }^{36}$ RODRIGUES, Silvio apud STOCO, Rui. Tratado de responsabilidade civil.5 ed., São Paulo: Revista dos Tribunais, 2001. p. 604.

37 LOPES, Christian Sahb Batista. A mitigação dos prejuízos no direito contratual. Tese (Doutorado em Direito) - Programa de Pós-Graduação em Direito da Faculdade de Direito, Universidade Federal de Minas Gerais, Belo Horizonte, 2011. Disponível em: <http://www.bibliotecadigital.ufmg.br/dspace/bitstream/handle/1843/BUOS-

8MQG8H/tese__christian_s_b_lopes__a_mitiga_o_dos_preju_zos_no_direito_contra tual.pdf?sequence=1>. Acesso em 22/10/2013. p. 154 .

${ }^{38}$ LOPES, Christian Sahb Batista. A mitigação dos prejuízos no direito contratual. Tese (Doutorado em Direito) - Programa de Pós-Graduação em Direito da Faculdade de Direito, Universidade Federal de Minas Gerais, Belo Horizonte, 2011. Disponível em: <http://www.bibliotecadigital.ufmg.br/dspace/bitstream/handle/1843/BUOS8MQG8H/tese__christian_s_b_lopes__a_mitiga_o_dos_preju_zos_no_direito_contra tual.pdf?sequence=1>. Acesso em 22/10/2013. p. 158 . 
com a boa-fé, sendo possível justificar o ônus de evitar os danos através da boa-fé objetiva. ${ }^{39}$

Ainda, a vedação do abuso de direito apenas poderá servir de alicerce se seus efeitos não se limitarem à esfera indenizatória, tendo em vista que "a norma da mitigação introduz a impossibilidade de que o credor obtenha a reparação pelos danos que poderia ter evitado e não a responsabilidade civil do credor por algum prejuízo"40.

No tocante à fundamentação da teoria dos danos evitáveis na proibição do venire contra factum proprium, esse é o fundamento menos aceito pelos autores que já abordaram o tema.

A proibição de venire contra factum proprium consiste na proteção que uma parte possui contra aquela que pretende realização de uma ação contrária a que fora previamente acordada, ou seja, realizar um comportamento diverso do que fora anteriormente assumido. ${ }^{41}$

Os que discordam da fundamentação da mitigação na proibição de venire contra factum propium abordam basicamente os seguintes argumentos:

O duty to mitigate the loss não corresponde a uma modalidade autônoma de abuso de direito, a situação de produção ou agravamento de dano por conduta da própria vítima se insere em figura típica já consagrada do abuso de direito: o venire contra factum proprium. A fundamentação do duty to mitigate com base na proibição de comportamento contraditório (venire contra factum proprium) é inviável porque não há como reconhecer na conduta da vítima de não evitar o agravamento do próprio prejuízo (principalmente por omissão) a aptidão para gerar no ofensor a confiança de que ela não mais iria pleitear reparação pela integralidade dos danos

\footnotetext{
${ }^{39}$ Idem. p. 159.

${ }^{40}$ Idem. p. 161.

${ }^{41}$ GONÇALVES, Carlos Roberto. Direito civil brasileiro: contratos e atos unilaterais. 9 ed., São Paulo: Saraiva, 2011. v. 3. p. 60.
} 
sofridos, elemento fundamental para a figura do venire. ${ }^{42}$

A proibição de venire contra factum propium encontra seu fundamento na proteção da confiança de que a parte não praticará atos incompatíveis com sua conduta anterior.

Por conseqüência, "o comportamento do credor (deixar que ocorram danos evitáveis) não gera confiança do devedor, assim como esse não alterou suas próprias ações em razão dessa suposta confiança de continuidade da primeira conduta do credor" ${ }^{\prime 3}$, sendo portanto, inaplicável a proibição de venire contra factum propium, no âmbito da teoria do duty to mitigate the loss.

\section{APLICAÇÃO DO DEVER DE MITIGAR NA RESPONSABILIDADE EXTRACONTRATUAL}

Não obstante a aplicação da teoria do dever de mitigar o dano no campo da responsabilidade contratual, em decorrência da violação da boa-fé objetiva, há entendimentos de que essa também pode ser aplicada no campo da responsabilidade extracontratual, apesar de pouco se falar a esse respeito, conforme se analisa adiante:

Como é possível perceber, os autores e até mesmo a jurisprudência se concentram no dever de mitigar o prejuízo em relação aos contratos. Todavia, nada

\footnotetext{
42 DIAS, Daniel Pires Novais. O duty to mitigate the loss no direito civil brasileiro e o encargo de evitar o próprio dano. Revista Eletrônica do Curso de Direito da UNIFACS. Salvador, n. 139, janeiro, 2012. Disponível em: <http://www.revistas.unifacs.br/index.php/redu/article/view/1894>. Acesso em 03/06/2014.

43 LOPES, Christian Sahb Batista. A mitigação dos prejuízos no direito contratual. Tese (Doutorado em Direito) - Programa de Pós-Graduação em Direito da Faculdade de Direito, Universidade Federal de Minas Gerais, Belo Horizonte, 2011. Disponível em: <http://www.bibliotecadigital.ufmg.br/dspace/bitstream/handle/1843/BUOS8MQG8H/tese__christian_s_b_lopes__a_mitiga_o_dos_preju_zos_no_direito_contra tual.pdf?sequence=1>. Acesso em 22/10/2013. p. 169 .
} 
impede que a teoria seja aplicada também para a responsabilidade extracontratual. ${ }^{44}$

Como justificativa para a aplicação do duty to mitigate the loss no âmbito da responsabilidade extracontratual, tem-se que a aplicação da evitabilidade irá decorrer do abuso de direito, previsto no artigo 187 do Código Civil.

Neste sentido:

O duty to mitigate the loss encontra sua forma de operacionalização para a responsabilidade extracontratual na teoria do abuso de direito. Tratase de nítida aplicação da função pretoriana de corrigir eventuais equívocos na relação obrigacional para se aproximar cada vez mais do justo no caso concreto. $^{45}$

Christian Sahb Batista Lopes explica brevemente, a possibilidade de aplicação da mitigação na responsabilidade extracontratual a partir do abuso de direito:

A boa-fé objetiva está prevista expressamente no artigo 422 do Código Civil, que está inserido na Parte Especial, no capítulo relativo aos contratos. Portanto, poder-se-ia argumentar que a mitigação, como corolário da boa-fé objetiva prevista no artigo 422, apenas seria aplicável ao inadimplemento de obrigações contratuais. Por outro lado, o artigo 187, que fundamentaria positivamente a aplicação da evitabilidade pela via do abuso de direito, está incluído na Parte Geral e, portanto, poderá ser aplicado tanto à responsabilidade extra-contratual quando a contratual. Em outros termos, para que o exercício do direito a indenização não seja abusivo,

\footnotetext{
${ }^{44}$ O Dever de Mitigar o Prejuízo (Duty to Mitigate the Loss) e a Responsabilidade Civil do Estado.

Disponível em: <http://www.apeam.org.br/2012/controlsites/imgeditor/File/Arquivo_tese\%2045.pdf>. Acesso em: 05/12/2013. p. 10.

45 Ibidem.
} 
o seu titular deverá ter agido de acordo com a boa-fé, de maneira leal e correta, tentando minimizar os prejuízos pelo emprego de esforços razoáveis, seja seu direito pleiteado com base em um contrato ou com base na responsabilidade aquiliana. ${ }^{46}$

Christian Sahb Batista Lopes expõe em sua tese um julgado que aplica a teoria da mitigação na responsabilidade extracontratual proferido pelo Tribunal de Justiça de Minas Gerais ${ }^{47}$, que segundo ele, apesar de ter mencionado expressamente o artigo 422 do Código Civil, afirmou que a regra da mitigação aplicada à responsabilidade extracontratual é a da proibição do abuso de direito, conforme artigo 187 do Código Civil. ${ }^{48}$

Desta forma, apesar de ainda pouco difundido o estudo da aplicação da teoria da mitigação dos danos no âmbito da responsabilidade extracontratual, acredita-se ser possível sua aplicação com fundamento no abuso de direito.

\section{CONCLUSÃO}

A partir das breves explanações acerca da teoria duty to mitigate the loss objetivou-se analisar, sinteticamente, os principais aspectos desse tema ainda pouco explorado pela doutrina brasileira.

A crescente aplicação da teoria do duty to mitigate the loss no Brasil está caminhando bem, porém acredita-se que ainda há que se reali-

${ }^{46}$ LOPES, Christian Sahb Batista. A mitigação dos prejuízos no direito contratual. Tese (Doutorado em Direito) - Programa de Pós-Graduação em Direito da Faculdade de Direito, Universidade Federal de Minas Gerais, Belo Horizonte, 2011. Disponível em: <http://www.bibliotecadigital.ufmg.br/dspace/bitstream/handle/1843/BUOS-

8MQG8H/tese__christian_s_b_lopes__a_mitiga_o_dos_preju_zos_no_direito_contra tual.pdf?sequence=1>. Acesso em 22/10/2013. p. 159 .

47 TJ-MG Processo n. ${ }^{\circ}$ 1.0701.07.183692-1/001, Relator: WAGNER WILSON, data de julgamento: 11/03/2009.

48 LOPES, Christian Sahb Batista. A mitigação dos prejuízos no direito contratual. Tese (Doutorado em Direito) - Programa de Pós-Graduação em Direito da Faculdade de Direito, Universidade Federal de Minas Gerais, Belo Horizonte, 2011. Disponível em: <http://www.bibliotecadigital.ufmg.br/dspace/bitstream/handle/1843/BUOS-

8MQG8H/tese__christian_s_b_lopes__a_mitiga_o_dos_preju_zos_no_direito_contra tual.pdf?sequence=1>. Acesso em 22/10/2013. p. 228. 
zar muitos estudos visando o aperfeiçoamento da teoria tratada neste trabalho.

Apesar de a norma referente ao dever de mitigar as próprias perdas ainda não estar positivada, sua aplicação aos casos práticos com fundamento nos artigos 422 e 187 do Código Civil, através da violação do princípio da boa-fé objetiva é totalmente aceitável e necessária.

Conjuntamente, chegou-se à inferência de que o dever de mitigar, assim como o parágrafo único do artigo 944 do Código Civil, constitui exceção ao disposto no caput desse artigo, ou seja, exceção ao princípio da reparação integral do dano.

Outrossim, entende-se que é perfeitamente possível a aplicação da mitigação no campo da responsabilidade extracontratual em decorrência da teoria do abuso de direito, porém, nota-se que ainda são necessários estudos mais aprofundados acerca do tema.

Finalmente, conclui-se que o dever de o credor mitigar as próprias perdas é claramente uma forma de se reduzir o ônus do devedor no cumprimento das obrigações, visto que não faz sentido que esse arque com prejuízos que poderiam ser facilmente evitados pelo credor, se esse agisse em consonância com a boa-fé objetiva.

\section{REFERÊNCIAS BIBLIOGRÁFICAS}

CAVALIERI FILHO, Sergio. Programa de responsabilidade civil. 10. ed. São Paulo: Atlas, 2012.

CAPIBERIBE, Denise de Araújo. O princípio da boa-fé objetiva e sua evolução doutrinária e jurisprudencial ao longo dos 10 anos de edição do novo código civil. Disponível em: <http://www.emerj.tjrj.jus.br/serieaperfeicoamentodemagistrados/p aginas/series/13/volumeI/10anosdocodigocivil_117.pdf > Acesso em: 03/12/2013.

DIAS, Daniel Pires Novais. O duty to mitigate the loss no direito civil brasileiro e o encargo de evitar o próprio dano. Revista Eletrônica do Curso de Direito da UNIFACS. Salvador, n. 139, janeiro, 2012. Disponível em: <http://www.revistas.unifacs.br/index.php/redu/article/view/1894>. Acesso em 03/06/2014. 
FLUMIGNAN, Silvano J. G. O Dever de Mitigar o Prejuízo (Duty to Mitigate the Loss) e a Responsabilidade Civil do Estado. In: XXXVIII Congresso Nacional de Procuradores de Estado, 2012, Foz do Iguaçu. Anais do XXXVIII Congresso Nacional de Procuradores de Estado, 2012. Disponível em: <http://www.apeam.org.br/2012/controlsites/imgeditor/File/Arquiv o_tese\%2045.pdf>. Acesso em: 05/12/2013.

GAGLIANO, Pablo Stolze. Editorial 13 duty to mitigate. Disponível em: <http://professor.ucg.br/siteDocente/admin/arquivosUpload/15449/ material/Editorial13.pdf>. Acesso em 02/06/2014.

. ; PAMPLONA FILHO; Rodolfo. Novo curso de direito civil: contratos. 8 ed. São Paulo: Saraiva, 2012, v.4.

. Novo curso de direito civil: responsabilidade civil. 10 ed. São Paulo: Saraiva, 2012, v.3.

GONÇALVES, Carlos Roberto. Direito civil brasileiro: contratos e atos unilaterais. 9 ed., São Paulo: Saraiva, 2011. v. 3.

. Direito civil brasileiro, volume IV: responsabilidade civil. 4 ed. São Paulo: Saraiva, 2009. v. 4.

LOPES, Christian Sahb Batista. A mitigação dos prejuízos no direito contratual. Tese (Doutorado em Direito) - Programa de PósGraduação em Direito da Faculdade de Direito, Universidade Federal de Minas Gerais, Belo Horizonte, 2011. Disponível em: <http://www.bibliotecadigital.ufmg.br/dspace/bitstream/handle/184 3/BUOS-

8MQG8H/tese__christian_s_b_lopes__a_mitiga_o_dos_preju_ zos_no_direito_contratual.pdf?sequence $=1>$. Acesso em 22/10/2013.

ONU. Assembleia Geral das Nações Unidas. Convenção da ONU sobre os contratos de compra e venda internacional de mercadorias. Disponível em: <http://www.globalsaleslaw.org/_temp/ CISG_portugues.pdf $>$. Acesso em 04/12/2013.

SANSEVERINO, Paulo de Tarso V. O Princípio da Reparação Integral e os Danos Pessoais. Disponível em: <http://www.cartaforense. com.br/conteudo/artigos/o-principio-da-reparacao-integral-e-osdanos-pessoais/4768>. Acesso em: 04/12/2013.

STOCO, Rui. Tratado de responsabilidade civil, 6 ed., São Paulo: Revista dos Tribunais, 2004.

SUPERIOR TRIBUNAL DE JUSTIÇA. Princípio da boa-fé objetiva é consagrado pelo STJ em todas as áreas do direito. Disponível em: 
<http://www.stj.jus.br/portal_stj/publicacao/engine.wsp?tmp.area= 398\& tmp.texto=108925>.Acesso em: 03/12/2013.

TARTUCE, Flávio. A boa-fé objetiva e a mitigação do prejuízo pelo credor. Esboço do tema e primeira abordagem. 2005. Disponível em:

<http://www.flaviotartuce.adv.br/index2.php?sec=artigos\&totalPag $\mathrm{e}=2>$. Acesso em 03/12/2013.

Manual de direito civil. Rio de Janeiro: Forense; São Paulo: MÉTODO. 2011. v. único.

VENOSA, Silvio de Salvo. Direito Civil: responsabilidade civil. 10. ed. São Paulo: Atlas, 2010, v. 4. 